\title{
Análise da Relação entre Investimentos Socioambientais e a InClusão de Empresas no ÍlNdice de SUSTentabilidade EMPRESARIAL (ISE) DA BM\&FBOVESPA
}

\author{
Analysis of the Relationship between Social and Environmental \\ Investment and Inclusion of Companies in Corporate \\ Sustainability Index of BM\&FBOVESPA
}

\begin{abstract}
Márcio André Veras Machado
Professor do Programa de Pós-Graduação em Administração, Universidade Federal da Paraíba - João Pessoa - PB, Brasil. E-mail: mavmachado@hotmail.com.
\end{abstract}

Marcelo Álvaro da Silva Macedo

Professor do Programa de Pós-Graduação em Ciências Contábeis, Universidade Federal do Rio de Janeiro -Rio de Janeiro - RJ, Brasil.E-mail: malvaro.facc.ufrj@gmail.com.

\section{Márcia Reis Machado}

Professora do Programa Multiinstitucional e Inter-regional de Pós-Graduação em Ciências Contábeis, Universidade Federal da Paraíba - João Pessoa - PB, Brasil.E-mail: marciareism@hotmail.com.

José Ricardo Maia de Siqueira

Professor do Programa de Pós-Graduação em Ciências Contábeis, Universidade Federal do Rio de Janeiro - Rio de Janeiro - RJ, Brasil.E-mail: jrms@facc.ufrj.br.

\section{Resumo}

Este artigo objetiva verificar a relação entre investimentos socioambientais e a inclusão das empresas no Índice de Sustentabilidade Empresarial (ISE) da BM\&FBOVESPA, por meio da aplicação de regressão logística. Para tanto, foram analisadas informações relativas aos investimentos ambientais e sociais internos e externos, retirados dos balanços sociais das empresas sob análise. A amostra foi formada por empresas elegíveis para compor a carteira ISE, no período de dezembro de 2009 a dezembro de 2010. De acordo com os resultados obtidos, pode-se concluir que existe relação entre os investimentos socioambientais e o ingresso das empresas na carteira ISE da BM\&FBOVESPA. Isso demonstrou que os investimentos das empresas realizados $e$ evidenciados em questões socioambientais são entendidos como indício de comprometimento real com a responsabilidade social e sustentabilidade

\section{Abstract}

This paper aims to investigate the relationship between social and environmental investments and the inclusion of companies in the Corporate Sustainability Index of BM\&FBOVESPA, by applying logistic regression. For this, we analyzed information relating to internal and external social and environmental investments, from the social balance of companies. The sample consisted of companies eligible for inclusion in the portfolio ISE in the period of December 2009 to December 2010. According to the results, we can conclude that there is a relationship between environmental investments and entry of firms in the portfolio ISE of BM\&FBOVESPA, showing that investment made and evidenced in social and environmental issues is a sign of real commitment to social responsibility and sustainability and not simply a form of accountability of the funds invested. As 
e não simplesmente uma forma de prestação de contas dos recursos aplicados. Quanto às variáveis utilizadas, investimentos sociais internos (II), externos (IE) e ambientais (IA), observou-se que IE é a melhor proxy para explicar essa relação, ou seja, os resultados sugerem que empresas que investem recursos em prol da comunidade, seja voluntariamente ou por meio dos tributos, o que é ou pelo menos deveria ser um recurso aplicado na sociedade, tem mais chances de entrar na composição da carteira ISE.

Palavras-chave: Investimentos Socioambientais. Índice de Sustentabilidade Empresarial. Regressão Logística.

\section{InTRODUÇÃo}

O cenário de negócios está mudando radicalmente. Com a consolidação do processo de globalização da economia, a informação trafega com uma grande velocidade em diversas mídias. Assim, as externalidades das empresas, sejam positivas ou negativas, tornam-se disponíveis a todos.

Em épocas passadas, ressaltam Macedo et al. (2007), um acidente que causasse danos ao ambiente poderia passar despercebido. $\mathrm{O}$ trabalho infantil ou demissões em massa ocupavam pouco espaço na mídia ou no ideário popular. Porém, hoje, a sociedade civil organizada cobra sistematicamente uma postura ética e coerente por parte das empresas e de seus gestores. Cobradas pela sociedade, as organizações hoje estão diante de um dilema: maximizar lucros a quaisquer esforços vale a pena?

Isso tudo vem se revelando num maior questionamento por parte da sociedade. Em outras palavras, os lucros cada vez mais altos aferidos pelas empresas geram um comportamento de atenção, fiscalização $e$, em alguns casos, de contestação por parte da sociedade organizada.

Para Dias e Siqueira (2006), durante muitos anos, diversas organizações apenas se preocupavam com a obtenção de lucros cada vez maiores, sugando da sociedade na qual estavam inseridas tudo o que fosse necessário para o alcance desse objetivo, deixando, frequentemente, nada ou quase nada em troca.

Com o passar do tempo, foi possível perceber o surgimento e o incremento dos movimentos sociais no seio da população, cobrando melhores condições the variables used, internal social investment (II), External (IE) and environmental (IA), we found that IE is the best proxy to explain this relationship. In other words, the results suggest that companies that invest resources in favor of community, either voluntarily or through taxes, which is or should be a resource applied in society, has more chances of entering the ISE portfolio composition.

Key words: Environmental Investments. Corporate Sustainability Index. Logistic Regression.

de trabalho, respeito ao meio ambiente, redução das desigualdades sociais e raciais, dentre outras mudanças. Isso fez com que as organizações passassem a dar maior importância para esses fatores que, até pouco tempo, eram menosprezados. (DIAS; SIQUEIRA, 2006)

De uma maneira geral, percebe-se que a sociedade não espera apenas lucros das empresas, mas que invistam em preservação e reparo dos danos causados ao meio ambiente, assegurem saúde e segurança aos empregados, consumidores e a comunidade local. (DEEGAN; RANKIN, 1997).

Especificamente com relação ao meio ambiente, nota-se que a sociedade parece demandar maior accountability por parte das empresas. De acordo com Labatt e White (2002), a atenção acerca da gestão ambiental tem crescido vertiginosamente em todos os segmentos do mercado. Nesse sentido, as empresas são cada vez mais exigidas a contribuir para o desenvolvimento econômico sustentável. (PINTO; RIBEIRO, 2004)

Inúmeros são os motivos que levam as empresas a aderir ao movimento pelo social, razões essas que nem sempre são assumidas publicamente. Diante dessa preocupação com a responsabilidade social e a sustentabilidade empresarial, medidas foram desenvolvidas para avaliar a valorização das ações de empresas que investem em responsabilidade social e ambiental, pois os investidores consideram que essas empresas gerem valor para os acionistas no longo prazo, tendo em vista que estão mais preparadas para enfrentar riscos econômicos, sociais e ambientais.

Em 1999, foi criado nos EUA o Dow Jones Sustainability (DSJI) - Índice de Sustentabilidade Dow Jones 
- primeiro índice a avaliar o desempenho financeiro das empresas líderes em sustentabilidade.

No Brasil, o primeiro fundo de investimento composto por empresas reconhecidas por desenvolverem boas práticas de responsabilidade social, ambiental e corporativa foi o Fundo Ethical, criado em 2001 pelo Banco ABN AMRO. Em 2005, a BOVESPA, hoje BM\&FBOVESPA, lançou o Índice de Sustentabilidade Empresarial (ISE), indicador composto de ações emitidas por empresas rentáveis que apresentam alto grau de comprometimento com sustentabilidade $e$ responsabilidade social.

Com base no exposto, questiona-se: qual arelação entre investimentos socioambientais e o ingresso das empresas no Índice de Sustentabilidade Empresarial (ISE) da BM\&FBOVESPA?

Sendo assim, o objetivo deste estudo é verificar seexiste relação entre os investimentos socioambientais e a inclusão das empresas no Índice de Sustentabilidade Empresarial (ISE) da Bovespa, por meio da aplicação de regressão logística às informações de empresas elegíveis para compor a carteira ISE, no período de dezembro de 2009 a dezembro de 2010.

Este artigo está estruturado em cinco partes, incluindo a introdução. A seguir, apresenta-se a revisão da literatura, a qual contempla o processo de construção da carteira teórica do ISE e os investimentos socioambientais. Na terceira parte, define-se o proceder metodológico. Na quarta parte, apresentam-se os resultados da pesquisa. Na quinta parte, a conclusão.

\section{Revisão da Literatura}

Teorias com a dos stakeholders, da legitimidade e institucional têm sido utilizadas para fundamentar estudos que buscam averiguar as práticas de disclosure social e ambiental (AZIZUL; DEEGAN, 2008). Embora o presente artigo trate dos investimentos sociais $e$ ambientais, tais teorias não podem ser consideradas para a fundamentação teórica do estudo, pois essas teorias não explicam e não dizem respeito à inclusão de empresas na carteira ISE. Por tanto, este estudo está alicerçado no objetivo da carteira ISE, que consiste em refletir uma carteira composta de ações de empresas com reconhecido comprometimento com a respon- sabilidade social $e$ a sustentabilidade, $e$ a suposição que os investimentos sociais $e$ ambientais refletem o comprometimento da empresa com a responsabilidade social e a sustentabilidade.

Assim, a revisão da literatura é dividida em duas seções. A primeira trata da Responsabilidade Sociambiental, como ponto de partida para as discussões deste trabalho. A segunda apresenta o índice de Sustentabilidade Empresarial (ISE).

\subsection{Responsabilidade Socioambiental}

A partir dos anos de 1950, observou-se uma mudança significativa na forma como as pessoas enxergavam a relação entre negócios e sociedade (LANTOS, 2001). Diversos fatores, como por exemplo, os desastres ambientais, as guerras $e$ as mudanças ocorridas na sociedade, afetaram o ambiente de negócios e tornaram os problemas socioambientais mais aparentes.

Conforme descrito por Monzoni, Biderman e Brito (2006), a preocupação com a ética e a transparência não é nova. Nos anos de 1960, conceitos como responsabilidade socioambiental corporativa e prestação de contas nasceram embaladas nas discussões sobre a Guerra do Vietnã, o Apartheid, a luta pelos direitos civis nos Estados Unidos, dentre outros. Nos anos de 1980 e de 1990, multiplicaram-se essas iniciativas com discussões na temática ambiental, fomentadas pelo crescimento do movimento ambientalista.

Ainda segundo os autores, no século XXI, surge a agenda da sustentabilidade, reconhecendo os vários problemas sociais e ambientais não tratados pelos sistemas econômicos, com o incremento das pressões da sociedade, exigindo mais responsabilidades das empresas em lidar com os problemas mundiais, muitos deles causados pelas externalidades dessas.

Segundo Oliveira (2008), não existe uma definição consensual sobre o que seja responsabilidade socioambiental. Não obstante, Daft (1997) apresenta um bom conceito, no qual essa responsabilidade é entendida como a obrigação da gerência organizacional de decidir e empreender ações que melhorem o bem-estar social e vão ao encontro dos interesses da sociedade e da organização.

Para autores como Melo Neto e Froes (1999), Tenório (2004), Ashley (2002), Parente e Gelman (2006) 
e Oliveira (2005), além do Instituto Ethos (2006), a responsabilidade social pode ser conceituada como um compromisso da empresa em relação à sociedade, cuja participação das empresas não se limita somente a gerar lucros, empregos e ao pagamento de impostos. Essa é uma forma de gestão definida pela relação ética e transparente que a empresa tem com todos os públicos com os quais ela se relaciona, sendo vista, portanto, como uma forma de accountability do desempenho empresarial, no que tange a sua maneira de agir, de impactar e de se relacionar com seus stakeholders. Em outras palavras, a responsabilidade social tem como principal característica a coerência ética nas práticas e relações com seus diversos públicos.

Há grande controvérsia sobre o desenvolvimento de ações de responsabilidade socioambiental por parte das organizações e sua aceitação pelos gestores. O conflito existente encontra-se nas teorias dos stockholders e dos stakeholders, em que cada grupo possui uma lógica negando e incentivando as práticas de responsabilidade socioambiental.

Segundo Friedman (1970), na teoria dos stockholders (ou shareholders), a única responsabilidade socioambiental de uma organização é a geração de lucros e a riqueza para seus acionistas, sendo sua responsabilidade máxima, portanto, o aumento do desempenho econômico. Quaisquer ações diferentes dessa podem colocar em risco a sobrevivência da empresa, além de dar origem a um problema de agência entre os acionistas e os gestores. Nesse sentido, ressaltam Brealey e Myers (2000), o administrador deve nortear suas ações no sentido de agir segundo os interesses dos proprietários - os acionistas.

Nessa linha, essa teoria mostra uma relação negativa entre responsabilidade socioambiental $e$ performance financeira, em que as responsabilidades adicionais que não sejam relacionadas ao incremento dos resultados financeiros colocam as empresas em desvantagem em relação a organizações que possuam menores, ou mesmo inexistentes, ações e práticas de responsabilidade socioambiental.

Já na teoria dos stakeholders, Freeman (1994) afirma que a gestão com base nesse público envolve a alocação de recursos organizacionais e considera os impactos dessa alocação em vários grupos de interesse dentro e fora da organização. Essa teoria pode ser vista, segundo Lea (1999), como uma resposta à visão da maximização única da riqueza dos acionistas (teoria dos stockholders), pois sugere que haja atenção por parte da empresa a uma multiplicidade de grupos relacionados com ela.

Esse ideário relaciona o desempenho financeiro com os stakeholders, afirmando que nesse cenário há uma relação positiva, não existindo qualquer desvio na função da empresa. Assim sendo, mesmo que seja difícil agregar o econômico e o social, de forma a medir os efeitos para stakeholders e stockholders de forma integrada, o resultado final da atividade empresarial precisa levar em consideração retornos que agradem não somente aos acionistas, mas também às demais partes interessadas.

Contudo, Jensen (2001) contesta esse pensamento afirmando que as organizações que adotam a teoria dos stakeholders acabarão passando por problemas de ordem gerencial, conflitos internos, ineficiência e, possivelmente, acabarão fracassando. Algumas empresas, segundo Rezende e Santos (2006), entretanto, perceberam que suas atuações não se restringem meramente ao campo econômico. Segundo os autores, isso acontece porque essas atuações se relacionam $e$ interagem com vários segmentos que podem interferir na condução de seus negócios.

Portanto, a visualização do ambiente em que a empresa opera, no tocante aos agentes que a influencia e que são influenciados por suas ações (tendo tais influências uma relação custo-benefício), faz com que ela atue com parâmetros relacionados aos vários stakeholders. Para isso, é importante definir, medir e monitorar os interesses deles, além de associá-los aos indicadores de desempenho da empresa.

A teoria dos stakeholders pode ser vista como aquela que preconiza a congruência entre os objetivos empresariais e socioambientais, já que elesestariam interligados ou, nas palavras de Drucker (2001), uma vez que as instituições somentepodem existir dentro de um ambiente socioambiental e são, de fato, órgãos da sociedade, tais problemas socioambientais as afetam. Drucker (2001) afirma, assim, que é difícil a existência de uma organização saudável em uma sociedade que não seja também sã.

Além disso, na teoria dos stakeholders, é assumida implicitamente a necessidade da existência de um equilíbrio nas ações de cunho socioambiental no cerne da empresa. Se uma empresa vai assumir uma 
postura socioambientalmente responsável, ela não pode se descuidar de sua atividade-fim; não pode se esquecer de que necessita alcançar um nível mínimo de lucratividade, para assegurar a continuidade das operações; não pode se descuidar de ser uma empresa inovadora, lançando novos produtos que estejam em conformidade com os anseios do mercado; não pode deixar de recrutar as melhores mentes disponíveis, para manter ou aumentar o nível de competitividade da organização; e não pode se esquecer que a sociedade não tem nada a ganhar e tudo a perder, se a capacidade da instituição de desempenhar sua tarefa específica for reduzida ou prejudicada. Isso exige que os gestores aliem dois conceitos: sustentabilidade $e$ valor ao acionista. (DRUCKER, 2001)

Nesse ponto, cabe destacar que o debate atual centra-se na sustentabilidade dos negócios. Segundo Brundtland et al. (1991, p. 46), "[...] o desenvolvimento sustentável é aquele que atende às necessidades do presente sem comprometer a possibilidade de as gerações futuras atenderem às suas próprias necessidades". No contexto dos negócios, para Vellani e Ribeiro (2006), a sustentabilidade tem três dimensões: a econômica, a social e a ambiental. Essas dimensões são conhecidas como Triple BottomLine (TBL) da sustentabilidade de um negócio.

O TBL reflete a necessidade das empresas serem gerenciadas com foco na sustentabilidade econômica, ao gerenciar empresas lucrativas e geradoras de valor; na sustentabilidade social, ao estimular a educação, cultura, lazer e justiça social à comunidade; e na sustentabilidade ecológica, ao manter ecossistemas vivos, com diversidade e vida. (VELLANI; RIBEIRO, 2006)

De acordo com Oliveira (2008) e Siqueira (2009), é possível observar diferentes abordagens de responsabilidade socioambiental, desde a ampla perspectiva fundamentada na teoria dos stakeholders até a limitada abordagem cristalizada na visão da teoria dos stockholders. A diferença básica entre as duas é uma questão de amplitude de visão, no que se refere às possibilidades das empresas terem benefícios financeiros com seus investimentos socioambientais. Enquanto a teoria dos stockholders parece ter uma visão de sistema fechado de empresa, voltado para racionalização de operações, maximização de eficiência e redução de custo, a teoria dos stakeholders tem uma visão de empresa como sistema aberto que afeta e é afetado pelo meio que o cerca.
Cada vez mais a imagem que as empresas gostariam de passar a seus clientes seria a de uma empresa ética. Segundo Oliveira, Daher e Oliveira (2006), as organizações querem, na verdade, demonstrar que são inatacáveis; alinhadas com a moral do tempo; $e$ sintonizadas com os costumes vigentes.

Em síntese, o que se espera, de acordo com Macedo et al. (2009), é que ao adicionar às suas competências básicas a conduta ética e socioambientalmente responsável, as empresas conquistem o respeito das pessoas e das comunidades atingidas por suas atividades, o engajamento de seus colaboradores e a preferência dos consumidores.

Oliveira (2005) ressalta que muitas empresas estão cada vez mais se empenhando em ações na área socioambiental dentro e fora de suas instalações e tentando se mostrar mais transparentes e receptivas ao diálogo com a sociedade. Ainda, segundo Oliveira (2005), além de maior interesse dos acionistas em informações socioambientais de suas empresas, a relação com as partes legitimamente interessadas, os stakeholders, tem mudado, passando a envolver uma maior transparência e a prestação de contas a diversos atores sociais, que até então não eram tão importantes no processo decisório.

Porém, um ponto crucial deve ser levantado nessa discussão de comportamento ético e socioambientalmente responsável, segundo Oliveira (2008). As questões sociais podem ser enfrentadas como resultado de motivações egoístas ou altruísticas. A decisão com base egoísta é aquela em queo autor da ação é motivado por algum interesse individual, percebido ou não. Já as preocupações com motivação altruística são aquelas que surgem em função de uma percepção de que um desequilîbrio social precisa ser corrigido, por ser injusto. Não há nenhum interesse subliminar, trata-se de fazer o certo por ser certo.

Tais motivações, apesar de serem conceitualmente fáceis de serem diferenciadas, são difíceis de serem detectadas na prática, ao se analisar as decisões organizacionais envolvendo o tema social. Paula, Pinto e Paiva (2002) afirmam que tanto o comprometimento ético com a sociedade, quanto o discurso ideológico que viabiliza sua permanência no mercado estão presentes nas políticas e práticas de gestão socialmente responsáveis desenvolvidas pelas empresas. Muito provavelmente, as motivações egoístas ou altruísticas 
devam ser consideradas como pontos extremos dentro de um continuum e as decisões empresariais seriam uma combinação de ambas, ora pendendo para uma extremidade ora pendendo para outra.

Para Dias e Siqueira (2006), a comunicação entre os gestores de uma organização e os stakeholders é frequentemente a chave dos dilemas da responsabilidade socioambiental. Um dos papéis fundamentais dos primeiros seria informar a estratégia da empresa, bem como os objetivos do empreendimento para o longo prazo, sendo que essas informações devem ser claras, a fim de que não proporcionem dúvidas sobre seu entendimento. Em síntese, os autores afirmam que, por meio dessas informações, os stakeholders poderiam concluir se a empresa é ou não socioambientalmente responsável e, conhecendo melhor o negócio, poderiam tomar mais conscientemente decisões do tipo "onde investir seu dinheiro" ou "que produtos comprar".

Segundo Adams (2004), foi em meados dos anos de 1980 que houve um incremento significativo da evidenciação socioambiental por parte das empresas e daí deu-se início, na academia, a uma linha de pesquisa que tem como principal foco o estudo do que e de como as empresas fazem essa evidenciação.

Nos últimos tempos, com a crescente internacionalização dos negócios, as organizações perceberam a importância da responsabilidade socioambiental dos negócios agora incorporar-se às práticas contábeis $e$ financeiras. Projetos, práticas, estatísticas são informações que precisam de forma específica de compilação e divulgação; torna-se imprescindível, então, o conceito de balanço social.

De acordo com Mattila (2009), o que trouxe essa maior atenção à responsabilidade socioambiental nos últimos tempos foi um melhor entendimento de seus benefícios potenciais para a competitividade das empresas, através, principalmente, da promoção da imagem corporativa. Nesse contexto, acrescentam Brown e Deegan (1998) e Deegan, Rankin e Tobin (2002), não se pode deixar de ressaltar o que mostra a Teoria da Legitimidade, no que diz respeito à motivação e aos incentivos que as empresas têm para fazer disclosure socioambiental.

Nesse sentido, surge, então, o conceito de balanço social. Para Tinoco (1984, p. 10),
[...] balanço social é um instrumento de gestão e de informação que visa reportar informações de cunho econômico e social do que aconteceu $e$ acontece numa entidade, aos mais diferentes usuários, dentre estes os assalariados.

Segundo Melo Neto e Froes (1999), não é de agora que as empresas estão desenvolvendo uma consciência social corporativa. O aspecto social do setor empresarial teve início na década de 1970, com o aumento da contestação da expansão econômica quantitativa, cuja expressão máxima foi o primeiro relatório do Clube de Roma, também denominado Relatório Meadows, sobre os limites dos crescimentos.

A França foi o primeiro país a implantar uma lei sobre o balanço social, sendo essa lei posta em prática, pela primeira vez, no ano de 1979, submetendo as empresas que possuíam 300 ou mais funcionários a divulgar o mesmo. Essa lei é a denominada Lei n. 77.769, de 12 de julho de 1977, mais conhecida como rapport, ou relatório, Sudreau. No Brasil, a ideia de balanço social surgiu no início da década de 1980 e teve o sociólogo Betinho como seu grande defensor. Por meio do Instituto Brasileiro de Análises Sociais e Econômicas(IBASE), entidade a qual presidia, Betinho iniciou uma verdadeira cruzada em prol do balanço social.

Tenório (2004) ilustra que o balanço social surgiu com a crescente demanda, por parte da sociedade, de informações a respeito dos impactos que as atividades empresariais exercem sobre os trabalhadores, a sociedade, a comunidade e o meio ambiente. Ainda, segundo Tenório (2004), os relatórios tradicionais priorizam informações de ordem financeira, econômica e patrimonial e não abordam elementos qualitativos ou o fazem superficialmente, sendo, portanto, insuficientes para a avaliação do desempenho empresarial.

De acordo com Melo Neto e Froes (1999), o balanço social representa o nível de compromisso com a busca de soluções para os problemas sociais do país. O balanço compreende dois tipos de ações: ações sociais direcionadas para os empregados e seus familiares, em especial no campo da educação, saúde, segurança do trabalho, remuneração e benefícios; e ações sociais voltadas para a sociedade, como educação, cultura, esporte, lazer, meio ambiente, dentre outras. 
Tinoco (2001) afirma que o balanço social é um documento importante, espelho da situação social na empresa, ele testemunha o clima que a rege. Plataforma de cooperação ou de reivindicação, ele inaugura de maneira implícita uma nova era nos relatórios entre a direção e os assalariados. Já segundo Tenório (2004), o balanço social é um instrumento de informação da empresa para a sociedade, por meio do qual a justificativa para sua existência deve ser explicitada. Em síntese, essa justificativa deve provar que o seu custo/ benefício é positivo, porque agrega valor à economia $e$ à sociedade, porque respeita os direitos humanos de seus colaboradores e, ainda, porque desenvolve todo o seu processo operacional sem agredir o meio ambiente.

Tenório (2004) destaca, ainda, os benefícios proporcionados pela implantação do balanço social: a identificação do grau de comprometimento social da empresa com a sociedade, os empregados e o meio ambiente; a evidenciação, por meio de indicadores, das contribuições à qualidade de vida na sociedade; a avaliação da administração através de resultados sociais, e não somente financeiros.

Porém, dois grandes problemas vêm sendo apresentados nos estudos realizados por diversos autores, como Deegan, Rankin e Tobin (2002) e Jones, Comfort e Hillier (2005). O primeiro é a ausência de evidenciação dos aspectos negativos em diversos balanços sociais publicados atualmente, o que pode ser considerado um viés na utilização de suas informações. O segundo diz respeito à existência de uma diferença substancial na natureza e nos conteúdos dos relatórios sociais, gerando, dentre outros problemas, dificuldade de comparação.

\section{2 Índice de Sustentabilidade Empresarial (ISE)}

Seguindo uma tendência das principais bolsas do mundo, em dezembro de 2005, a Bolsa de Valores de São Paulo (BOVESPA), hoje BM\&FBOVESPA, em conjunto com outras instituições - Associação Brasileira das Entidades Fechadas de Previdência Complementar (ABRAPP); Associação Nacional dos Bancos de Investimento (ANBID); Associação dos Analistas e Profissionais de Investimentos do Mercado de Capitais (APIMEC); Instituto Brasileiro de Governança Corporativa (IBGC);InternationalFinance Corporation (IFC); e
Instituto Ethos e Ministério do Meio Ambiente - lançou o Índice de Sustentabilidade Empresarial (ISE) com o objetivo de

[...] refletir o retorno de uma carteira composta por ações de empresas com reconhecido comprometimento com a responsabilidade social e a sustentabilidade empresarial, e também atuar como promotor das boas práticas no meio empresarial brasileiro. (ISE - METODOLOGIA COMPLETA, 2010, p. 3)

O ISE foi desenvolvido com base no conceito de "Triple Bottom Line", que envolve a avaliação de elementos ambientais, sociais e econômico-financeiros de forma integrada, além de indicadores de governança corporativa, características gerais e natureza do produto. (ISE - METODOLOGIA COMPLETA, 2010)

Para fazer parte desse índice, as ações devem atender cumulativamente os seguintes critérios: ser uma das 150 ações com maior índice de negociação nos 12 meses anteriores à avaliação;ter sido negociada em pelo menos $50 \%$ dos pregões ocorridos nos doze meses anteriores à formação da carteira; atender aos critérios de sustentabilidade estabelecidos pelo Conselho do ISE. (ISE - METODOLOGIA COMPLETA, 2010)

São excluídas da carteira as ações que:a empresa emissora entrar em regime de recuperação judicial ou falência;no caso de oferta pública que resultar em retirada de parcelas significativas de suas ações do mercado;se durante a vigência da carteira ocorrer evento que venha a afetar significativamente seus níveis de sustentabilidade e responsabilidade social. (ISE - METODOLOGIA COMPLETA, 2010)

O ISE medirá o retorno de uma carteira teórica composta pelos papéis que atenderem atodos os critérios discriminados anteriormente, com vigência de um ano, ponderados pelo respectivo valor demercado de suas ações disponíveis para negociação, ou seja, serão excluídas as ações de propriedade do controlador. Destaca-se que, a partir de 2009, a participação de uma empresa no ISE não poderá ser superior a $15 \%$. (ISE - METODOLOGIA COMPLETA, 2010)

A primeira carteira ISE teve vigência de dezembro de 2005 a novembro de 2006 e era composta por 28 empresas de 12 setores. O setor predominante nessa carteira era o de Energia Elétrica, correspondendo a mais de $32 \%$ da carteira (Quadro 1), seguido do setor 
Financeiro (17,86\%), Papel e Celulose (10,71\%) e Ma- alto impacto sobre o meio ambiente. Assim, observa-se terial de Transporte $(7,14 \%)$. Conforme o FTSE4Good que a primeira carteira, bem como as demais apresen(apud BARBOSA, 2007), quanto ao critério ambiental, tadas a seguir, é constituída predominantemente por o setor de Geração de Energia é classificado como de empresas que apresentam um maior risco ambiental.

\begin{tabular}{|c|c|c|c|c|c|c|c|c|c|c|}
\hline \multirow{3}{*}{ SETOR } & \multicolumn{10}{|c|}{ CARTEIRA - ISE } \\
\hline & \multicolumn{2}{|c|}{$2005 / 2006$} & \multicolumn{2}{|c|}{$2006 / 2007$} & \multicolumn{2}{|c|}{$2007 / 2008$} & \multicolumn{2}{|c|}{ 2008/2009 } & \multicolumn{2}{|c|}{$2009 / 2010$} \\
\hline & 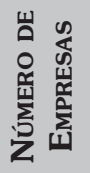 & $\%$ & 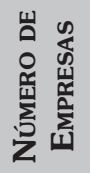 & $\%$ & 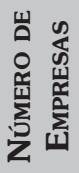 & $\%$ & 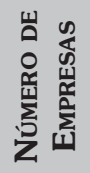 & $\%$ & 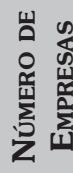 & $\%$ \\
\hline Energia & 9 & 32,14 & 8 & 23,53 & 11 & 34,38 & 11 & 36,67 & 11 & 32,35 \\
\hline Financeiro & 5 & 17,86 & 5 & 14,71 & 3 & 9,38 & 4 & 13,33 & 5 & 14,71 \\
\hline $\begin{array}{l}\text { Siderurgia e } \\
\text { metalurgia }\end{array}$ & 1 & 3,57 & 3 & 8,82 & 3 & 9,38 & 2 & 6,67 & 2 & 5,88 \\
\hline $\begin{array}{l}\text { Construção e } \\
\text { transporte }\end{array}$ & 1 & 3,57 & 1 & 2,94 & 0 & 0,00 & 0 & 0,00 & 1 & 2,94 \\
\hline Alimentos & 1 & 3,57 & 1 & 2,94 & 2 & 6,25 & 2 & 6,67 & 1 & 2,94 \\
\hline Papel e celulose & 3 & 10,71 & 3 & 8,82 & 3 & 9,38 & 2 & 6,67 & 1 & 2,94 \\
\hline $\begin{array}{l}\text { Produtos de } \\
\text { uso pessoal }\end{array}$ & 1 & 3,57 & 1 & 2,94 & 1 & 3,13 & 1 & 3,33 & 1 & 2,94 \\
\hline $\begin{array}{l}\text { Máquinas e } \\
\text { equipamentos }\end{array}$ & 1 & 3,57 & 0 & 0,00 & 1 & 3,13 & 0 & 0,00 & 1 & 2,94 \\
\hline Petroquímico & 1 & 3,57 & 4 & 11,76 & 3 & 9,38 & 1 & 3,33 & 1 & 2,94 \\
\hline Saúde & 1 & 3,57 & 1 & 2,94 & 1 & 3,13 & 2 & 6,67 & 1 & 2,94 \\
\hline Madeira e papel & 0 & 0,00 & 0 & 0,00 & 0 & 0,00 & 1 & 3,33 & 2 & 5,88 \\
\hline Telecomunicações & 0 & 0,00 & 0 & 0,00 & 0 & 0,00 & 2 & 6,67 & 3 & 8,82 \\
\hline $\begin{array}{l}\text { Água e } \\
\text { saneamento }\end{array}$ & 0 & 0,00 & 0 & 0,00 & 1 & 3,13 & 1 & 3,33 & 1 & 2,94 \\
\hline $\begin{array}{l}\text { Material de } \\
\text { transporte }\end{array}$ & 2 & 7,14 & 2 & 5,88 & 2 & 6,25 & 1 & 3,33 & 1 & 2,94 \\
\hline Mineração & 0 & 0,00 & 0 & 0,00 & 0 & 0,00 & 0 & 0,00 & 1 & 2,94 \\
\hline Transporte & 2 & 7,14 & 4 & 11,76 & 1 & 3,13 & 0 & 0,00 & 0 & 0,00 \\
\hline Consumo cíclico & 0 & 0,00 & 1 & 2,94 & 0 & 0,00 & 0 & 0,00 & 0 & 0,00 \\
\hline $\begin{array}{l}\text { Previdência } \\
\text { e seguros }\end{array}$ & 0 & 0,00 & 0 & 0,00 & 0 & 0,00 & 0 & 0,00 & 1 & 2,94 \\
\hline Total & 28 & 100 & 34 & 100 & 32 & 100 & 30 & 100 & 34 & 100 \\
\hline
\end{tabular}

Quadro 1: Composição das carteiras ISE por setor

Fonte: Dados da pesquisa 
A segunda carteira ISE, renovada em 2006 e com vigência até novembro de 2007, era composta de 43 papéis de 34 empresas, correspondendo a 12 setores. Como já relatado, o setor de Energia Elétrica foi o mais representativo desta carteira, participando com aproximadamente $23 \%$ do total. O setor financeiro passou a representar $14 \%$. O setor de Siderurgia e Metalurgia, que na primeira carteira representava aproximadamente $3,5 \%$, passou a ter uma representatividade de $8,82 \%$ no índice. Vale salientar que, assim como o setor energético, o setor de siderurgia e metalurgia também é considerado como de alto impacto ambiental. (Quadro 1).

A terceira carteira ISE, com vigência de dezembro de 2007 a novembro de 2008, foi composta de 40 ações de 32 empresas, representando 12 setores da econômica. Nessa carteira, assim como nas anteriores, apresentou como setor mais representativo o de energia, com aproximadamente $36 \%$, seguido pelos setores Financeiro, Papel e Celulose e Siderurgia e Metalurgia, ambos com uma participação em torno de 6\%. (Quadro 1).

Em 2008, a carteira foi novamente renovada. Dessa vez, com vigência de dezembro de 2008 a novembro de 2009, sendo composta de 38 ações de 30 empresas, representando 12 setores da econômica. Nessa carteira, também foi predominante a participação do setor de energia (36,67\%), seguido pelos setores Financeiro $(13,33 \%)$ e Telecomunicações (6,67\%) (Quadro 1).

Por fim, a última carteira compreendida no estudo, formada em 2009, com vigência até dezembro de 2010, era composta por 34 empresas, representando 16 setores da economia. Observa-se que, mesmo com o limite de $15 \%$ da participação de uma empresa no índice, conforme a metodologia do ISE, o setor elétrico manteve elevada participação (32,35\%).

Teorias com a dos stakeholders, da legitimidade e institucional têm sido utilizadas para fundamentar estudos que buscam averiguar as práticas de disclosure social e ambiental (AZIZUL; DEEGAN, 2008). Embora o presente artigo trate dos investimentos sociais $e$ ambientais, tais teorias não podem ser consideradas para a fundamentação teórica do estudo, pois essas teorias não explicam e não dizem respeitoà inclusão de empresas na carteira ISE. Por tanto, este estudo está alicerçado no objetivo da carteira ISE, que consiste em refletir uma carteira composta de ações de empresas com reconhecido comprometimento com a responsabilidade sociale a sustentabilidade, e a suposição que os investimentos sociais e ambientais refletem o comprometimento da empresa com a responsabilidade social e a sustentabilidade.

\section{Proceder Metodológico}

A descrição dos aspectos metodológicos desse trabalho está dividida em quatro partes: tipo de pesquisa, coleta de dados e amostra, variáveis e modelo econométrico.

\subsection{Tipo de Pesquisa}

Quanto à caracterização da pesquisa, optou-se por um estudo empírico-analítico, que, segundo Martins (2002, p. 34), "[...] são abordagens que apresentam em comum a utilização de técnicas de coleta, tratamento e análise de dados marcadamente quantitativos [...]. Tais abordagens têm forte preocupação com a relação causal entre variáveis. A validação da prova científica é buscada por meio de testes dos instrumentos, graus de significância e sistematização das definições operacionais".

\subsection{Coleta de Dados e Amostra}

Como o objetivo do estudo é averiguar a relação dos investimentos sociais e ambientais das empresas e seu ingresso no índice ISE, tomou-se o cuidado de incluir no estudo apenas empresas com potencial de ingresso no referido índice.

Conforme estabelece a BM\&FBOVESPA, somente empresas socialmente responsáveis, sustentáveis e rentáveis podem ingressar no índice ISE. Para tanto, existe uma seleção entre as empresas detentoras dos 150 papéis mais líquidos negociados na BM\&FBOVESPA, as quais são denominadas de empresas elegíveis.

Visto que a metodologia utilizada para selecionar as empresas sofreu alterações no último ano, 2009, optou-se por considerar, neste estudo, apenas as empresas elegíveis para compor a carteira do ISE, no período de dezembro de 2009 a novembro de 2010. 
Devido à escolha desse período, as variáveis utilizadas, conforme apresentado a seguir, são referentes ao exercício anterior, 2008, o qual serviu de base para a seleção final da carteira. Assim, utilizou-se a listagem das empresas elegíveis, contendo 135 empresas, disponibilizado pela BM\&FBOVESPA, como, inicialmente, o universo da pesquisa.

Com base na listagem das empresas elegíveis, consultou-se o banco de dados do Ibase, a fim de coletar as informações referentes aos investimentos socioambientais. No entanto, no referido banco de dados, somente estava disponível o balanço social de duas empresas. Para viabilizar o estudo, foi realizada pesquisa no site de todas as empresas elegíveis, em busca do balanço social modelo Ibase, bem como consultados os relatórios anuais, relatórios de sustentabilidade, demonstrações financeiras publicadas e balanços sociais, resultando na coleta de dados de 45 empresas.

\subsection{Variáveis}

As variáveis estudadas consistem nos investimentos socioambientais efetuados pelas empresas. Como não há a obrigatoriedade de divulgação de tais informações, bem como um modelo padrão seguido por todas as empresas, definiu-se, para fins deste trabalho, o modelo de balanço social sugerido pelo Ibase, como fonte da obtenção de tais informações.

A escolha do modelo de balanço social Ibase justifica-se pelo fato de ser simples e utilizado por muitas empresas, bem como já ter sido utilizado em diversos estudos. Assim, os investimentos socioambientais serão classificados em: Investimentos Internos (II), Investimentos Externos (IE) e Investimentos Ambientais (IA), conforme estabelece o balanço social Ibase.

Uma vez que o estudo compreende empresas de diversos setores e tamanhos, optou-se por não utilizar os investimentos pelo seu valor bruto, mas como um índice, calculado com base na receita líquida das empresas. Dessa forma, a métrica utilizada corresponde à parcela média da receita líquida destinada a tais investimentos:

$$
P I I=\frac{I I}{R L}
$$

$$
\begin{aligned}
& P I E=\frac{I E}{R L} \\
& P I A=\frac{I A}{R L}
\end{aligned}
$$

onde: $\mathrm{PII}=$ parcela da receita líquida de 2008 destinada a investimentos sociais internos; PIE $=$ parcela da receita líquida de 2008 destinada a investimentos sociais externos; PIA = parcela da receita líquida de 2008 destinada a investimentos ambientais; RL = receita líquida de 2008.

Destaca-se que a utilização da receita líquida como denominador deve-se a dois fatos: (1) disponibilidade dos dados e (2) utilização dessa variável como base de referência nos balanços sociais.

\subsection{Modelo Econométrico}

Analisou-se se há uma relação logística entre investimentos socioambientais e a inclusão das empresas no Índice de Sustentabilidade Empresarial (ISE) da BM\&FBOVESPA. Em função de a variável dependente ser dicotômica, fez-se uso da estatística multivariada regressão logística, por meio do modelo representado na Equação 4:

$$
P(C I S E)=\frac{1}{1+e^{-g(x)}} \text { em que, }
$$

$g(x)=\beta_{0}+\beta_{1} P I I_{i, t-1}+\beta_{2} P I E_{i, t-1}+\beta_{3} P I A_{i, t-1}+\mu_{i}($ Eq. 5)

onde: CISE - Ingresso na carteira ISE da Bovespa, Variável dependente, representada na presente pesquisa por uma variável dicotômica, recebendo 0 (Zero) se a empresa não entrou na carteira e 1 (Um) se a empresa entrou na carteira. $b_{0}$ a $b_{3}$-representam os coeficientes a estimar; PII $_{i, t-1}$ - parcela da receita líquida destinada a investimentos sociais internos; da empresa $i$, no período $t-1$. $\mathrm{PIE}_{i, t-1}$ - parcela da receita líquida destinada a investimentos sociais externos da empresa $i$, no período

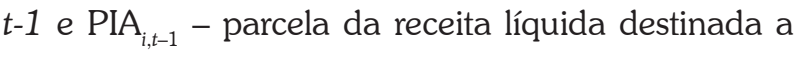
investimentos ambientais da empresa $i$, no período $t-1$.

A Regressão Logística é uma técnica estatística em que, com base nos dados de uma amostra específica, uma ou mais variáveis independentes são matematicamente combinadas para criar expectativas acerca da 
ocorrência ou não de um determinado evento incerto, o qual é expresso sob a forma de uma variável dependente dicotômica (ou seja, com valor "0" ou "1"). Tecnicamente, utiliza-se uma função logística para se determinar o logaritmo neperiano da razão de chances do evento em questão. (HAIR et al., 1998)

A regressão logística difere da regressão múltipla, no sentido de prevê diretamente a probabilidade de um evento ocorrer e da análise discriminante por envolver apenas duas categorias. Apesar de o valor da probabilidade ser uma medida métrica, podendo assumir quaisquer valores entre zero e um, seu valor previsto deve ser limitado, de modo a recair sempre dentro do referido intervalo.

Ao contrário da regressão múltipla, que faz uso do método dos mínimos quadrados ordinários, como método de estimação dos parâmetros, a regressão logística utiliza-se do método da máxima verossimilhança, quando se calcula a medida de ajuste geral do modelo, ou seja, utiliza-se uma forma iterativa para encontrar as estimativas mais prováveis para os parâmetros. (GUJARATI, 2000)

A regressão logística tem com vantagens: lidar com praticamente qualquer quantidade de variáveis independentes; não requer que as variáveis envolvidas apresentem propriedades especiais como ter distribuição normal e variâncias homocedásticas ou ser intervalar/razão; poder trabalhar com praticamente qualquer tipo de variável independente (dicotômica, ordinal ou contínua), incluindo combinações de tipos diferentes; como ocorre com qualquer tipo de análise de regressão com múltiplas variáveis, os efeitos de interação entre as variáveis são matematicamente eliminados. (HAIR et al., 1998)

\section{Análise dos Dados}

A análise de regressão logística foi efetuada, considerando as seguintes opções: Classificationplots; Hosmer-Lemeshowgoodness-of-fit; Include constant in model;Classificationcutoff: 0,5; Maximuminteration: 20; CI ofexp (B): $95 \%$.
Conforme Quadro 2, seis empresas que compõem a amostra foram exluídas do modelo, por não conter informações de II, IE ou IA. O Quadro 1 evidencia como as empresas seriam classificadas sem considerar as variáveis independentes. A priori, o modelo está sendo guiado apenas pelo status predominante. vinte empresas ingressaram na carteira ISE, sendo classificadas na categoria "sim", e 19 não ingressaram, sendo classificadas na categoria "não". Desse modo, a classificação estaria correta em aproximadamente $51,3 \%$ dos casos. Inicialmente, o modelo inclui apenas a constante, conforme Tabela 1.

\begin{tabular}{|c|c|c|c|c|c|}
\hline & \multicolumn{2}{|c|}{ OBSERVAdo } & \multicolumn{3}{|c|}{ Predito } \\
\hline & & \multicolumn{2}{|c|}{$\begin{array}{c}\text { INGRESSO } \\
\text { NA CARTEI- } \\
\text { RA ISE }\end{array}$} & $\begin{array}{c}\text { Percentual } \\
\text { CoRreto }\end{array}$ \\
\hline & & & Não & Sim & Não \\
\hline & \multirow{2}{*}{$\begin{array}{l}\text { Ingresso } \\
\text { na carteira } \\
\text { ISE }\end{array}$} & Não & 0 & 19 & 0 \\
\hline & & Sim & 0 & 20 & 100 \\
\hline $\begin{array}{l}0 \\
\text { ज़ } \\
\text { के }\end{array}$ & \multicolumn{2}{|c|}{ Percentual Geral } & \multicolumn{3}{|c|}{51,3} \\
\hline
\end{tabular}

a: Constante é incluída no modelo

b: Valor de corte é 5,0

Quadro 2: Quadro de Classificação a priori a, b

Fonte: Dados da pesquisa

Tabela 1: Variáveis Consideradas a priori

\begin{tabular}{|c|c|c|c|c|c|c|c|}
\hline $\begin{array}{c}\text { Step } \\
0\end{array}$ & Constant & 0,051 & 0,320 & 0,026 & 1 & 0,873 & 1,053 \\
\hline
\end{tabular}

Fonte: Dados da pesquisa

O objetivo da análise é fornecer parâmetros para verificar se a inclusão das variáveis independentes fornece uma classificação mais próxima da realidade, ao tempo que permite analisar quais variáveis explicam o ingresso das empresas no índice ISE. Conforme Quadro 1, classificando as observações apenas em função do status predominante na amostra, pode-se acertar aproximadamente $51,3 \%$ das vezes. É possível observar então que, se, ao incluir as variáveis independentes do nosso modelo, observa-se uma melhora na acurácia da classificação. 
A validação estatística do modelo é feita por meio dos testes e indicadores evidenciados nas tabelas 2, 3 e 4. Os Testes Step, Block e Model são utilizados para avaliar a hipótese de nulidade de todos os coeficientes. Os resultados indicam rejeição da hipótese nula a um nível de significância de $1 \%$, ou seja, pelo menos uma variável tem coeficiente significativamente diferente de zero, e comprovam a adequação do modelo, conforme Tabela 2. Portanto, o modelo pode ser utilizado para verificar se os investimentos socioambientais explicam o ingresso das empresas no índice ISE da BM\&FBOVESPA.

Tabela 2: Teste Omnibus Para os Coeficientes do Modelo

\begin{tabular}{|r|r|c|c|c|}
\hline & Chi-square & df & Sig. \\
\hline Step 1 & Step & 13,216 & 3 & 0,004 \\
\hline Block & 13,216 & 3 & 0,004 \\
\hline Model & 13,216 & 3 & 0,004 \\
\hline
\end{tabular}

Fonte: Dados da pesquisa

O teste -2 log likelihood (-2LL) indica o grau de ajustamento do modelo. Esse número não é interpretado diretamente, mas participa do cálculo do Model, Black e Step. Contudo, alguns autores, como Hair et. al. (1998), consideram que, quanto menor o -2LL, maior a capacidade preditiva do modelo. No modelo em análise, encontrou-se um valor de 40,823, conforme Tabela 3.

Tabela 3: Sumário do Modelo

\begin{tabular}{|l|c|c|c|}
\hline Step & $\begin{array}{c}-2 \text { Log } \\
\text { likelihood }\end{array}$ & $\begin{array}{c}\text { Cox \& Snell } \\
\text { R Square }\end{array}$ & $\begin{array}{c}\text { Nagelkerke } \\
\text { R Square }\end{array}$ \\
\hline 1 & $40,823(\mathrm{a})$ & 0,287 & 0,383 \\
\hline
\end{tabular}

a Estimation terminated at iteration number 5 because parameter estimates changed by less than ,001

Fonte: Dados da pesquisa

O poder explicativo do modelo é dado pelo indicador Nagelkerke $\mathrm{R}^{2}$, que representa uma adaptação do Cox \& Snell, fornecendo resultados compreendidos no intervalo de 0 a 1 . No presente estudo, tem-se o valor de 0,383 , indicando que $38,3 \%$ das variações registradas na variável dependente são explicadas pelo conjunto das variáveis independentes utilizadas.

A precisão do modelo é avaliada pelo Teste Hosmer e Lemeshow. Ele testa a hipótese nula de que não existem diferenças significativas entre os resultados preditos pelo modelo e os observados. Conforme Tabela 4, o nível de significância obtido é superior ao nível de $5 \%$, não se podendo rejeitar a hipótese nula, concluindo-se que inexistem diferenças significativas entre os resultados observados e os previstos pelo modelo. A Tabela 5 evidencia os dados utilizados para o cálculo do referido teste.

Tabela 4: Teste de Hosmer e Lemeshow

\begin{tabular}{|l|c|c|c|c|}
\hline Step & Chi-square & df & Sig. \\
\hline 1 & 4,318 & 8 & 0,827 \\
\hline
\end{tabular}

Fonte: Dados da pesquisa

Tabela 5: Tabela de Contigência Para o de Hosmer e Lemeshow

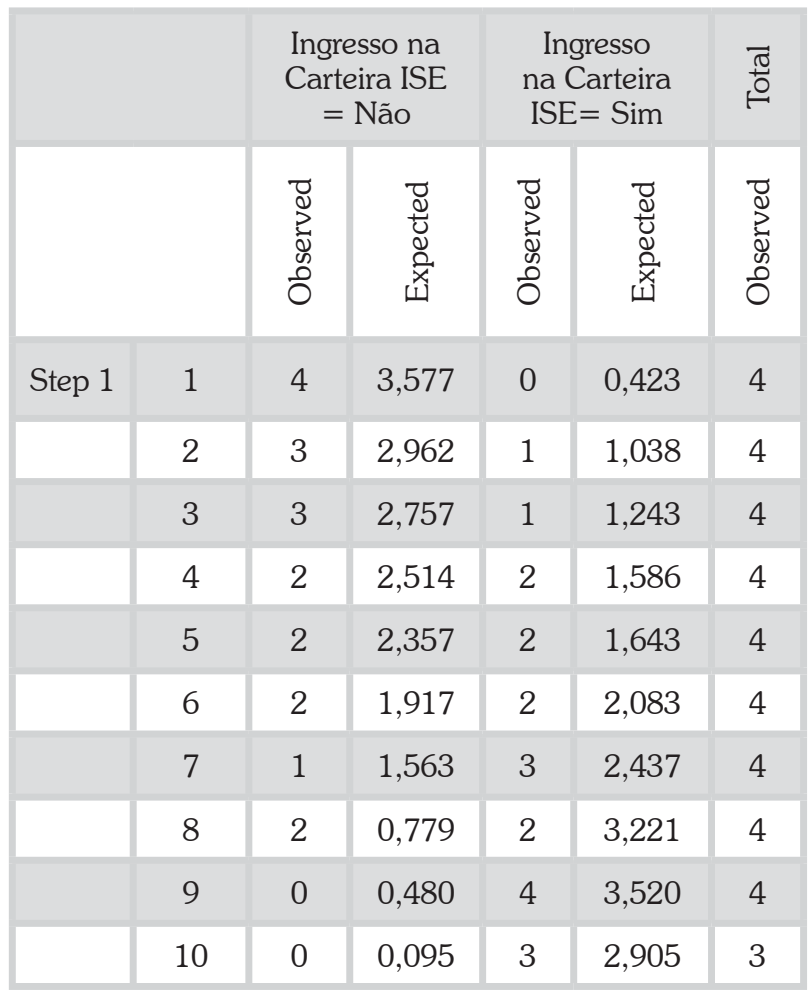

Fonte: Dados da pesquisa

O Quadro 3 evidencia que, com a inclusão das variáveis independentes, $69,2 \%$ das observações são classificadas corretamente, melhorando consideravelmente em relação ao modelo a priori (51,3\%). O passo seguinte foi averiguar quais variáveis apresentaram significância estatística, segundo o teste de Wald. 


\begin{tabular}{|c|c|c|c|c|c|}
\hline \multirow{6}{*}{$\begin{array}{l}0 \\
\text { ज्ञ } \\
\text { जी }\end{array}$} & \multicolumn{2}{|c|}{ Observado } & \multicolumn{3}{|c|}{ Predito } \\
\hline & & & \multicolumn{2}{|c|}{$\begin{array}{c}\text { INGRESSO } \\
\text { NA CARTEI- } \\
\text { RA ISE }\end{array}$} & $\begin{array}{c}\text { Percentual } \\
\text { Correto }\end{array}$ \\
\hline & & & Não & Sim & Não \\
\hline & \multirow{2}{*}{$\begin{array}{l}\text { Ingresso } \\
\text { na carteira } \\
\text { ISE }\end{array}$} & Não & 14 & 5 & 73,76 \\
\hline & & Sim & 7 & 13 & 65,0 \\
\hline & \multicolumn{2}{|c|}{ Percentual Geral } & \multicolumn{3}{|c|}{69,2} \\
\hline
\end{tabular}

a The cut value is, 500

Quadro 3: Classificação Final

Fonte: Dados da pesquisa

De acordo com a Tabela 6, a variável IE apresentou significância estatística ao nível de 5\%, enquanto as variáveis II e IA não se mostraram significativas, conforme teste de Wald.

Tabela 6: Significância das Variáveis do Modelo

\begin{tabular}{|c|c|c|c|c|c|c|c|}
\hline & & B & S.E. & Wald & df & Sig. & $\operatorname{Exp(B)}$ \\
\hline $\begin{array}{c}\text { Step } \\
1(\mathrm{a})\end{array}$ & II & $-1,728$ & 9,862 & 0,031 & 1 & 0,861 & 0,178 \\
\hline & IE & 7,898 & 3,104 & 6,475 & 1 & 0,011 & 2692,075 \\
\hline & IA & $-, 69,349$ & 57,200 & 1,470 & 1 & 0,225 & 0,000 \\
\hline $\begin{array}{c}\text { Cons- } \\
\text { tante }\end{array}$ & $-0,828$ & 0,795 & 1,805 & 1 & 0,298 & 0,437 \\
\hline
\end{tabular}

Fonte: Dados da pesquisa

Portanto, de acordo com os resultados obtidos, pode-se concluir que existe relação entre investimentos socioambientais e o ingresso das empresas na carteira ISE da Bovespa, sendo a variável IE a melhor proxy para explicar essa relação.

\section{Conclusão}

Diante da tendência mundial de investidores procurarem aplicações socialmente responsáveis, seja por uma questão de modismo ou porque consideram que empresas sustentáveis geram valor ao longo do tempo por estarem mais preparadas para enfrentar riscos econômicos, sociais e ambientais, índices constituídos por empresas com alto grau de comprometimento com questões socioambientais foram criados, a exemplo do índice ISE da BM\&FBOVESPA, que seleciona para compor essa carteira teórica empresas com alta liquidez e com reconhecido comprometimento com a responsabilidade social e sustentabilidade.

As empresas que compõem o ISE passam por processo seletivo que inclui várias etapas e fornecimento de informações adicionais, além das comumente evidenciadas nos relatório anuais e de sustentabilidade.

Como as informações socioambientais são voluntárias e não seguem um padrão, é muito difícil para o investidor, com base apenas nas informações fornecidas pelas empresas, avaliar e comparar o nível de comprometimento das empresas com questões socioambientais, muito embora já existam alguns modelos padronizados e bastante usado pelas empresas.

Diante disso, este estudo se propôs a verificar se os investimentos socioambientais evidenciados pelas empresas têm relação com a inclusão das empresas no Índice de Sustentabilidade Empresarial (ISE) da BM\&FBOVESPA, por meio da aplicação de regressão logística às informações de empresas elegíveis para compor a carteira ISE, no período de dezembro de 2009 a dezembro de 2010.

De acordo com os resultados obtidos, pode-se concluir que existe relação entre os investimentos socioambientais e o ingresso das empresas na carteira ISE da BM\&FBOVESPA, demonstrando que os investimentos das empresas, realizados e evidenciados em questões socioambientais, são entendido como indício de comprometimento real com a responsabilidade social e com a sustentabilidade e não simplesmente uma forma de prestação de contas dos recursos aplicados.

Nos resultados, tais considerações podem ser observadas pela qualidade do modelo proposto, tanto no que diz respeito aos testes executados, quanto na melhoria do poder explicativo a priori, já que o modelo apresentou um incremento de capacidade explicativa na ordem de quase $20 \%$, indo de $51,3 \%$ para $69,2 \%$ de observações classificadas corretamente.

Quanto as variáveis utilizadas, investimentos sociais internos (II), externos (IE) e ambientais (IA), observou-se que IE é a melhor proxy para explicar essa relação, ou seja, os resultados sugerem que empresas que investem recursos em prol da comunidade, seja voluntariamente ou por meio dos tributos, o que é ou pelo menos deveria ser um recurso aplicado na sociedade, tem mais chances de entrar na composição da carteira ISE. 
Cabe se destacar, contudo, que a efetiva mensuração da responsabilidade social se dá de forma mais ampla, não se limitando às três variáveis utilizadas neste estudo. Modelos de relatórios de sustentabilidade, como o proposto pela Global ReportingInitiative (GRI), têm trabalhado com uma ampla gama de indicadores, visando tornar claro o perfil social das organizações por meio da evidenciação não apenas dos impactos positivos das organizações, como feito neste artigo, mas também de suas externalidades negativas.

Sugere-se, portanto, estudos futuros que envolvam um conjunto mais amplo de indicadores de sustentabilidade, englobando inclusive aqueles que se relacionem às externalidades negativas da atividade econômica. Um estudo possível, seguindo essa linha, seria uma análise comparativa do grau de responsabilidade social de diferentes empresas utilizando a DEA $e$ indicadores propostos pela GRI. Outra possibilidade seria verificar a existência de diferenças significativas no grau de responsabilidade social, também mensurado por meio de indicadores da GRI, entre empresas participantes e não participantes de índices de ações com viés socioambiental.

Tais estudos, apesar de potencialmente envolverem uma massa de dados maior se aproximariam de um conceito mais rigoroso de responsabilidade social, indo, consequentemente, ao encontro de anseios que emanam de segmentos organizados da sociedade relacionados à identificação de esforços de desenvolvimento sustentável sob uma ótica não apenas econômica, mas também social e ambiental.

\section{REFERÊNCIAS}

ADAMS, C. A. The ethical, social and environmental reporting-performance portrayal gap. Accounting,

Auditing \& Accountability Journal, Bradford, v. 17, n. 5, p. 731-757, 2004.

ASHLEY, P. A. Ética e responsabilidade social nos negócios. São Paulo: Saraiva, 2002.

AZIZUL, Muhammad Islam; DEEGAN, Craing. Motivations for an organisation within a developing country to report social responsibility information: evidence from Bangladesh. Accounting, Auditing\& Accountability Journal, Bradford, v. 21, n. 6, p.850-868

\section{BARBOSA, P. R. A. Índice de sustentabilidade} empresarial da bolsa de valores de São Paulo (ISEBOVESPA): exame da adequação como referência para aperfeiçoamento da gestão sustentável das empresas e para formação de carteiras de investimento orientadas por princípios de sustentabilidade corporativa. 2007. 148f. Dissertação (Mestrado em Administração) - Universidade Federal do Rio de Janeiro - UFRJ, Instituto COPPEAD de Administração, 2007.

BOVESPA. Mercado: Ações - Índices. 2010. Disponível em: <http://bovespa.com.br>. Acesso em: 5 jan. 2010.

BREALEY, R. A.; MYERS, S. C. Principles of corporate finance. 6. ed. Boston: Irwin McGraw Hill, 2000.

BROWN, N.; DEEGAN, C. M.The public disclosure of environmental performance information - a dual test of media agenda setting theory and legitimacy theory.

Accounting and Business Research, Abingdon, v. 29, n. 1, p. 21-41, 1998.

BRUNDTLAND, G. et al. Nosso futuro comum. Rio de Janeiro: FGV, 1991.

DAFT, R. L. Management. Fort Worth: Dryden Press, 1997.

DEEGAN, C.; RANKIN, M.The materiality of environmental information to users of annual reports. Accounting,

Auditing \& Accountability Journal, Bradford, v. 10, n. 4, p. 562-583, 1997.

DEEGAN, C.; RANKIN, M.; TOBIN, J. An Examination of the Corporate Social and Environmental Disclosures of BHP from 1983-1997: A test of legitimacy theory. Accounting Auditing e Accountability Journal, Bradford, v. 15, n. 3, p. 312-343, 2002.

DIAS, L. N. S.; SIQUEIRA, J. R. M. Análise da evolução qualitativa dos balanços sociais da Petrobras no período de 2000 a 2004. In: CONGRESSO USP DE CONTROLADORIA E CONTABILIDADE, 6, 2006, São Paulo. Anais...São Paulo: 2006.

DRUCKER, P. A Administração. São Paulo: Nobel, 2001.

FREEMAN, R. E. The politics of stakeholders theory: some future directions. Business Ethics Quarterly, Willimantic, v. 4, n. 4, p. 409-422, 1994. 
FRIEDMAN, M. The social responsibility of business is increase its profits. New York Times Magazine, New York, n. 33, p. 122-126, set. 1970.

GUJARATI, D. N. Econometriabásica. 3. ed. São Paulo: Pearson, 2000.

HAIR JR., J. F. et al. Multivariate Data Analysis: with Readings. 5. ed. New Jersey: Prentice Hall, 1998.

JENSEN, M. C. Value maximization, stakeholder theory and the corporate objective function. Journal of Applied Corporate Finance, New York, v. 14, n. 3, p. 8-21, 2001. JONES, P.; COMFORT, D.; HILLIER, D. Corporate social responsibility and the UK's top ten retailers. International Journal of Retail e Distribution Management, Bradford, v. 33, n. 12, p. 882-892, 2005,

LABATT, S.; WHITE, R. Environmental finance. New York: Wiley, 2002.

LANTOS, G. P. The Boundaries of Strategic Corporate Social Responsibility. Journal of Consumer Marketing, Santa Barbara, v. 18, n. 7, p. 595-630, 2001.

LEA, D. Corporate and public responsibility, stakeholder theory and the developing world. Business Ethics: A European Review, Huddersfield, v. 8, n. 3, p. 151-162, 1999.

MACEDO, M. A. S. et al. Análise Comparativa do Desempenho Contábil-Financeiro de Empresas Socialmente Responsáveis. Revista Pensar Contábil, Rio de Janeiro, v. 11, n. 43, p. 15-23, 2009.

MACEDO, M. A. S. et al. Desempenho de empresas socialmente responsáveis: uma análise por índices contábilfinanceiros. Revista Produção Online, Edição Especial, Florianópolis, p. 1-22, dez. 2007.

\section{MARTINS, G. Manual para elaboração de} monografias e dissertações. 3. ed. São Paulo: Atlas, 2002.

MATTILA, M. Corporate social responsibility and image in organizations: for the insiders or the outsiders? Social

Responsibility Journal, Bradford, v. 5, n. 4, p. 540-549, 2009.
MELO NETO, F. P.; FROES, C. Q. Responsabilidade Social e Cidadania Empresarial: a administração do terceiro setor. Rio de Janeiro: Qualitymark, 1999.

MONZONI, M.; BIDERMAN, R.; BRITO, R. Finanças Sustentáveis e o Caso do Índice de Sustentabilidade Empresarial da Bovespa. In: SIMPÓSIO DE ADMINISTRAÇÃO DA PRODUÇÃO, LOGÍSTICA E OPERAÇÕES INTERNACIONAIS, 9, 2006, São Paulo. Anais... São Paulo: 2006.

\section{OLIVEIRA, J. A. P. Empresas na Sociedade:}

Sustentabilidade e Responsabilidade Social. Rio de Janeiro: Elsevier, 2008.

OLIVEIRA, J. A. P. Uma avaliação dos balanços sociais das 500 maiores. RAE Eletrônica, v. 4, n. 1, 2005. Disponível em:<www.rae.com.br/eletronica>. Acesso em: 10 jan. 2007.

OLIVEIRA, M. C.; DAHER, W. M.; OLIVEIRA, B. C. Responsabilidade social corporativa e geração de valor reputacional: estudo de multicaso, segundo o modelo de Hopkins, de empresas do setor energético do nordeste brasileiro. In: CONGRESSO USP DE CONTROLADORIA E CONTABILIDADE, 6, 2006, São Paulo. Anais... São Paulo: 2006.

\section{PARENTE, J.; GELMAN, J. J. Varejo e} responsabilidade social, visão estratégica e práticas no Brasil. Porto Alegre: Bookman, 2006.

PAULA, A. S. A.; PINTO, J. A. R.; PAIVA, K. C. M. Responsabilidade Social: Comprometimento Ético ou Discurso Ideológico? In: ASSEMBLÉIA DO CONSELHO LATINO-AMERICANO DE ESCOLAS DE ADMINISTRAÇÃO, 37, 2002, Porto Alegre. Anais... Porto Alegre: 2002.

PINTO, A.; RIBEIRO, M. Balanço Social: a avaliação das informações fornecidas por empresas industriais situadas no estado de Santa Catarina. Revista Contabilidade \& Finanças, São Paulo, n. 36, p. 21-34, 2004. 
REZENDE, I. A. C.; SANTOS, L. S. R. Análise da

Rentabilidade e Performance dos Investimentos

Socialmente Responsáveis: um estudo empírico no mercado brasileiro. In: ENCONTRO DA ASSOCIAÇÃO

NACIONAL DE PÓS-GRADUAÇÃO E PESQUISA EM

ADMINISTRAÇÃO, 30, 2006, Salvador. Anais... Salvador:

2006.

SIQUEIRA, J. R. M. Balanço Social: Evidenciação da Responsabilidade Social. In: FERREIRA, A. C. S.; SIQUEIRA, J. R. M.; GOMES, M. Z. (Org.). 2009.

Contabilidade Ambiental e Relatórios Sociais. São Paulo, Atlas.

TENORIO, F. G. Responsabilidade Social

Empresarial: teoria e prática. Rio de Janeiro: FGV, 2004.

TINOCO, J. E. P. Balanço social: uma abordagem da transparência e da responsabilidade pública das organizações.São Paulo: Editora Atlas, 2001.

TINOCO, J. E. P. Balanço social: uma abordagem sócio-econômica da contabilidade. São Paulo, 1984. 111 f. Dissertação (Mestrado em Contabilidade). Faculdade de Economia, Administração e Contabilidade da Universidade de São Paulo, 1984.

VELLANI, C. L.; RIBEIRO, M. S. A Sustentabilidade e a Contabilidade. In: SIMPÓSIO DE ADMINISTRAÇÃO DA PRODUÇÃO, LOGÍSTICA E OPERAÇÕES INTERNACIONAIS, 9, 2006, São Paulo. Anais... São Paulo: 2006. 